\title{
BMJ Open CT-defined visceral adipose tissue thresholds for identifying metabolic complications: a cross-sectional study in the United Arab Emirates
}

\author{
Sunmi Yoo (D) , ${ }^{1}$ Myung-Whun Sung, ${ }^{2,3}$ Hongdae Kim ${ }^{4,5}$
}

To cite: Yoo S, Sung M-W, Kim H. CT-defined viscera adipose tissue thresholds for identifying metabolic complications: a crosssectional study in the United Arab Emirates. BMJ Open 2020;10:e031181. doi:10.1136/ bmjopen-2019-031181

- Prepublication history and additional material for this paper are available online. To view these files, please visit the journal online (http://dx.doi. org/10.1136/bmjopen-2019031181).

Received 05 July 2019 Revised 01 April 2020 Accepted 25 June 2020
Check for updates

(C) Author(s) (or their employer(s)) 2020. Re-use permitted under CC BY-NC. No commercial re-use. See rights and permissions. Published by BMJ.

For numbered affiliations see end of article.

Correspondence to Dr Hongdae Kim; dr.thorr@gmail.com

\section{ABSTRACT}

Objectives Visceral adipose tissue (VAT) is closely related to obesity complications. We aimed to determine the optimal sex-specific and age-specific VAT thresholds for predicting metabolic complications among individuals living in the United Arab Emirates (UAE).

Design Retrospective cross-sectional study.

Setting We reviewed medical records of adults who visited a hospital in the UAE.

Participants A total of 369 subjects were included in the final analysis after application of inclusion and exclusion criteria.

Primary outcome measures The prevalence of metabolic syndrome (MES).

Results MES measures excluding waist circumference were present in $73.4 \%$ of women and $78.5 \%$ of men. VAT areas adjusted for age were significantly greater in the MES group compared with the non-MES group regardless of $\operatorname{sex}(p<0.05$ for all relations); however, subcutaneous adipose tissue areas adjusted for age were not significantly different. Areas under the curve used to predict MES were statistically significant for VAT and visceral to subcutaneous fat ratios among both men and women. Identified cut-off values of VAT to predict MES were $132.0 \mathrm{~cm}^{2}$ in both sexes for individuals under the age of 50 years. For those over 50 years of age, VAT thresholds were greater in women compared with men $\left(173 \mathrm{~cm}^{2}\right.$ vs $124.3 \mathrm{~cm}^{2}$, respectively).

Conclusions Optimal VAT cut-offs to predict MES were $132 \mathrm{~cm}^{2}$ for individuals under 50 years old living in the UAE. These measures are potential target visceral fat values that could be used to reduce obesity-related morbidity in populations with pre-existing metabolic complications.

\section{INTRODUCTION}

Visceral fat is an active organ used for energy storage and adipocyte metabolism. Visceral fat stores are closely related to obesity complications such as diabetes and fatty liver. ${ }^{1}$ Positive energy balance that ultimately results in obesity initially drives excess free fatty acids to subcutaneous adipose tissues (SAT). Once SAT storage capacity is reached or impaired, fat accumulates in areas outside the

\section{Strengths and limitations of this study}

- Obesity and its complications are prevalent in the United Arab Emirates (UAE), and this study determined the sex-specific and age-specific thresholds for abdominal adipose tissue areas.

- Study data were obtained through retrospective chart review and included body mass index, metabolic profiles (fasting plasma glucose, lipid profile, blood pressures), and abdominal adipose tissue areas quantified through CT.

- The study characterised the optimal threshold of visceral adipose tissue stores that correspond to metabolic complications related to obesity in a UAE population and compared these findings to those of previous studies examining other populations.

- More than half of the women had subcutaneous adipose tissue (SAT) areas greater than the CT imaging field, and if we include only women with appropriate regions of interest in the analysis, our results do not represent women with increased SAT.

- Due to the cross-sectional retrospective nature of this study, we did not have data on waist circumference or detailed personal histories, which may have resulted in overestimation of metabolic syndrome.

subcutaneous compartment, including the visceral adipose tissue (VAT). ${ }^{2}$ VAT could be considered as a marker of ectopic fat retained throughout the viscera, including the liver, heart, skeletal muscles and the vasculature. ${ }^{3}$

A critical VAT threshold has been proposed to correspond to the mass of VAT that results in the occurrence of metabolic abnormalities. This critical threshold was thought to have both individual and ethnic variability. ${ }^{4}$ Differences in adipose tissue distribution and characteristics have been studied in various ethnic populations. ${ }^{5-10}$ However, it is not yet known whether the critical VAT thresholds are also valid in populations with a high prevalence of metabolic diseases. The United Arab Emirates (UAE) has been shown to be a country with one of the fastest growing rates of obesity and 
obesity-related morbidity. Obesity prevalence in the UAE has been on the rise over the past decade and a recent study reported an overall incidence rate of $20 \% .{ }^{11}$ This trend has been directly associated with the rapid increase in diabetes prevalence $\mathrm{e}^{12}$ as well as resulting in ischaemic heart disease becoming the leading cause of death in the UAE. $^{13}$

We hypothesised that the threshold amount of VAT resulting in metabolic complications in people living in the UAE may be similar to that reported in previously published studies that assessed these values in individuals of different ethnic backgrounds. The aim of the study was to find the appropriate age-specific and sex-specific VAT thresholds capable of predicting metabolic complications among adults in the UAE who visited a specific hospital.

\section{SUBJECTS AND METHODS}

\section{Study subjects}

This retrospective, cross-sectional, observational study screened a total of 4177 adults aged between 20 years and 80 years who visited Sheikh Khalifa Specialty Hospital in the UAE and underwent abdominal CT scans and laboratory tests for metabolic complications starting from January 2016 through December 2017. The requirement for informed consent was waived due to the retrospective nature of the analyses. Abdominal CT scans were retrieved from the hospital's picture archiving and communication systems. Medical records and radiologist reports accompanying each scan were retrospectively reviewed.

Among the patients that were screened for inclusion and who underwent abdominal CT scans, subjects were excluded if they did not have laboratory tests to confirm metabolic abnormalities ( $\mathrm{N}=2115)$, had intra-abdominal abnormalities affecting fat distribution or metabolic complications, including abdominal injury $(\mathrm{N}=48)$ or surgery $(\mathrm{N}=17)$ at the time of study enrolment, had any previous history of bariatric surgery $(\mathrm{N}=16)$, were diagnosed with a myocardial infarct at the time of study enrolment $(\mathrm{N}=4)$, were diagnosed with malignant neoplasms within the past 5 years $(\mathrm{N}=534)$ or were women within 1 month of the postpartum period $(\mathrm{N}=1)$. Subjects who performed more than two CT examinations were included only once, based on the time of first examination. Subjects with abdominal adipose areas greater than the field of view were included and are also described separately in the online supplementary tables and figures.

Patients from the UAE and those from neighbouring Arab countries, including Egypt, Syria, Israel, Lebanon, Jordan, Iran, Turkey, Iraq, Saudi Arabia, Kuwait, Bahrain, Yemen, Oman and Qatar, were included in the final study population. Patients with nationalities from Southeast Asia, East Asia, Europe or Africa except Egypt were excluded from the study $(\mathrm{N}=39)$.

\section{Measurement of intra-abdominal adipose tissue}

Adipose tissue areas were measured for each subject using a CT scanner (Ingenuity 128, Philips Healthcare,
Eindhoven, the Netherlands) at the umbilicus level. The cross-sectional area $\left(\mathrm{cm}^{2}\right)$ of abdominal fat was calculated using Xelis 3D software (INFINITT Healthcare Co, Seoul, Korea) with attenuation values for the region of interest ranging between $-250 \mathrm{HU}$ and $-50 \mathrm{HU}$ using the histogram method. The technique used for adipose tissue area measurements in cross-sectional CT images has been previously standardised and validated. ${ }^{14}$ Two areas were obtained by drawing the outer and inner lines of the abdomen and back muscles. The VAT area was defined as intraperitoneal fat bound by parietal peritoneum or transversalis fascia, and the SAT area was defined as fat areas external to the abdomen and back muscles. Visceral-to-subcutaneous fat ratios (VSRs) were calculated from the obtained data. All measurements were individually performed by one researcher with more than 10 years of experience.

\section{Measurement of metabolic complications}

The data on patients' weights, heights and blood pressures were obtained from their medical records. Body mass index (BMI) was calculated by dividing weight $(\mathrm{kg})$ by height squared $\left(\mathrm{m}^{2}\right)$. Fasting plasma glucose (FPG), total cholesterol, low density lipoprotein cholesterol (LDL-C), high-density lipoprotein cholesterol (HDL-C) and triglyceride (TG) values were obtained from medical records. The data from blood samples following a minimum 10-hour fast collected within 30 days prior to or after abdominal CT scans were collected. Laboratory values were measured enzymatically using the cobas 6000 analyzer (Roche Diagnostics, Mannheim, Germany).

Metabolic complications in study participants were identified based on International Diabetes Federation (IDF) criteria $^{15}$ and included: systolic blood pressure $\geq 130 \mathrm{~mm}$ $\mathrm{Hg}$ or diastolic blood pressure $\geq 85 \mathrm{~mm} \mathrm{Hg}$ or treatment of previously diagnosed hypertension, FPG $\geq 100 \mathrm{mg} / \mathrm{dL}$ or treatment of previously diagnosed type 2 diabetes, TG levels $\geq 150 \mathrm{mg} / \mathrm{dL}$, and HDL-C levels $<40 \mathrm{mg} / \mathrm{dL}$ for men and $<50 \mathrm{mg} / \mathrm{dL}$ for women. Since the waist circumference data were not available in the medical record, metabolic syndrome (MES) was defined as having two or more previously mentioned metabolic abnormalities.

\section{Statistical analysis}

Statistical analyses were performed using PASW Statistics for Windows (IBM Corporation 2010, New York, USA). Independent sample t-tests and $\chi^{2}$ tests were used to analyse continuous and categorical variables, respectively, in order to examine differences in study population characteristics. Analysis of covariance was used to compare adiposity indices after adjusting for age between patients with or without metabolic complications.

A receiver-operating characteristics (ROC) analysis was performed, and the area under the curve (AUC) was analysed and presented along with $95 \%$ CIs in order to evaluate the utility of BMI, VAT, SAT and VSR as predictive markers for metabolic complications and its individual components, including hypertension, hyperglycaemia, 


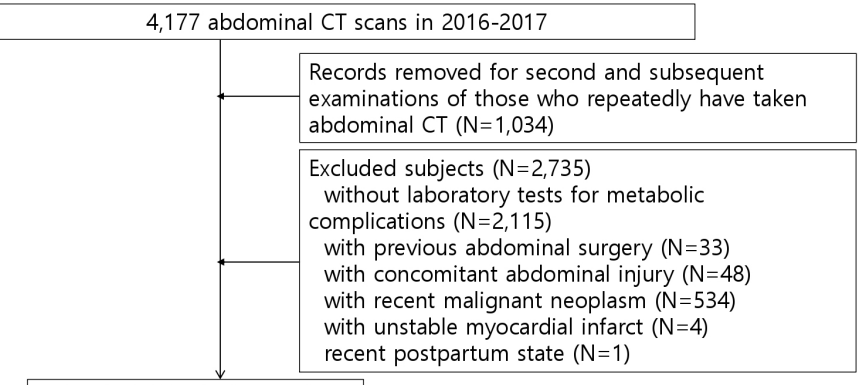

Total of 408 eligible adults

Excluded subjects with nationality other than the Middle East $(\mathrm{N}=39)$

Total of 369 adults included in the final analysis

Figure 1 Data collection and management.

high TG and low HDL-cholesterol levels. Cut-off values for VAT and VSR with maximised sensitivity and specificity were analysed using MedCalc software V.18.11 (MedCalc Software Bvba, Ostend, Belgium). The cut-off value data were stratified by age and sex. The sensitivity and specificity of each cut-off was determined using the Youden's Index. A value of $p<0.05$ was considered to be statistically significant.

\section{Patient and public involvement}

This research was done without patient involvement. Patients were not invited to comment on the study design and were not consulted to develop patient relevant outcomes or interpret the results. Patients were not invited to contribute to the writing or editing of this document for readability or accuracy.

\section{RESULTS}

\section{Subject characteristics}

A total of 369 from an initial study population of 4177 subjects were included in the final analysis. Figure 1 describes the inclusion and exclusion criteria used to select the study subjects.

Table 1 shows selected subjects characteristics stratified by sex. The mean age was $51.2 \pm 14.8$ years for women and $52.8 \pm 15.6$ years for men. More than half of the women $(52.1 \%)$ were over 50 years of age and $42.4 \%$ of the men were over 50 years of age. Figure 2 shows the distribution of the VAT, SAT and VSR by age group and sex. VAT values increased with age for both men and women, and remained constant after $50 \mathrm{~s}$. Mean BMI was $32.3 \pm 8.5 \mathrm{~kg} /$ $\mathrm{m}^{2}$ in women and $28.6 \pm 6.9 \mathrm{~kg} / \mathrm{m}^{2}$ in men. A relatively low proportion of subjects were ever-smokers $(0.5 \%$ in women vs $22.9 \%$ in men) or reported drinking alcohol (2.3\% in men only). More than $40 \%$ of all subjects had a history of hypertension. Diabetes was reported in $39.6 \%$ of women and $32.8 \%$ of men. The prevalence of MES excluding waist circumference measures was $73.4 \%$ in women and $78.5 \%$ in men.

Online supplementary figures show quartiles of VAT, SAT and VSR according to age group and sex among

\begin{tabular}{lll}
\hline Table 1 & \multicolumn{3}{l}{ Baseline characteristics of the subjects } \\
& $\begin{array}{l}\text { Female } \\
(\mathbf{N}=192)\end{array}$ & $\begin{array}{l}\text { Male } \\
\mathbf{( N = 1 7 7 )}\end{array}$ \\
\hline Age (years) & $51.2 \pm 14.8$ & $52.8 \pm 15.6$ \\
\hline Age $>50$ years old, N (\%) & $92(47.9)$ & $102(57.6)$ \\
\hline BMI (kg/m²) & $32.3 \pm 8.5$ & $28.6 \pm 6.9$ \\
\hline BMI $\geq 30 \mathrm{~kg} / \mathrm{m}^{2}, \mathrm{~N}(\%)$ & $110(57.9)$ & $55(31.8)$ \\
\hline Ever-smoker, N (\%) & $1(0.5)$ & $40(22.9)$ \\
\hline Alcohol drinking, N (\%) & $0(0)$ & $4(2.3)$ \\
\hline Diagnosed as hypertensive, & $80(41.7)$ & $72(40.7)$ \\
N (\%) & & \\
\hline Diagnosed as diabetic, N (\%) & $76(39.6)$ & $58(32.8)$ \\
\hline The UAE nationals, N (\%) & $177(92.2)$ & $163(92.1)$ \\
\hline Systolic BP (mm Hg) & $130.0 \pm 19.8$ & $134.6 \pm 20.4$ \\
\hline Diastolic BP (mm Hg) & $69.9 \pm 9.6$ & $73.9 \pm 10.7$ \\
\hline FPG (mg/dL) & $131.8 \pm 60.9$ & $129.2 \pm 48.5$ \\
\hline Total cholesterol (mg/dL) & $176.0 \pm 44.5$ & $160.4 \pm 48.7$ \\
\hline TG (mg/dL) & $132.9 \pm 80.4$ & $124.9 \pm 77.6$ \\
\hline HDL-C (mg/dL) & $45.7 \pm 15.8$ & $39.8 \pm 13.6$ \\
\hline LDL-C (mg/dL) & $105.9 \pm 38.5$ & $94.7 \pm 40.6$ \\
\hline MES except waist & $141(73.4)$ & $139(78.5)$ \\
circumference, N (\%) & & \\
\hline
\end{tabular}

Expressed as mean $\pm \mathrm{SD}$ or $\mathrm{N}(\%)$.

$\mathrm{BMI}$, body mass index; BP, blood pressure; FPG, fasting plasma glucose; HDL-C, high-density lipoprotein cholesterol; LDL-C, lowdensity lipoprotein cholesterol; MES, metabolic syndrome; TG, triglyceride; UAE, United Arab Emirates.

subjects with adequate region of interest for abdominal adipose area (empty columns, women; hatched columns, men).

\section{Metabolic complications and adipose tissue areas}

Table 2 displayed data that compared the metabolic complications and adipose tissue areas in subjects with and without MES stratified by sex. The MES group had a higher age compared with the non-MES group irrespective of sex. Mean BMI was similar among the two groups for both women and men. High FPG or use of diabetes medication were the most common metabolic complications in both men and women with MES. High TG levels were the least common among all study subjects. In more than half of women, the skin surface exceeded the CT image field of view and the SAT area was underestimated, but the overall prevalence was similar among subjects with or without MES.

VAT areas adjusted for age were significantly greater in the MES group compared with the non-MES group regardless of sex ( $<<0.05$ for all relations). However, SAT areas adjusted for age were not different between the MES group and the non-MES group in both women and men. VSRs adjusted for age were significantly greater in the MES group compared with the non-MES group only among men ( $p=0.249$ in women; $p=0.027$ in men). 
A

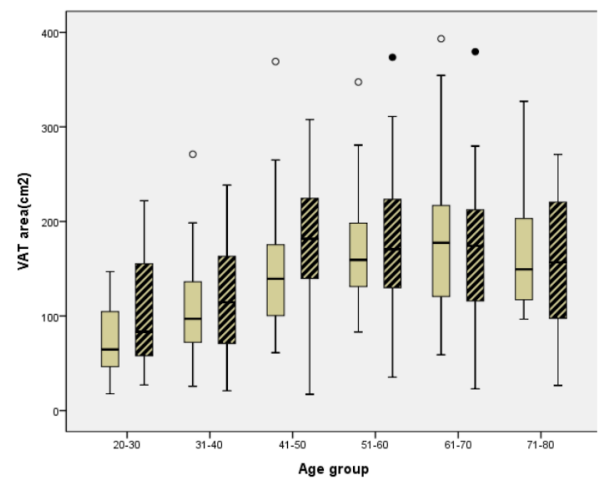

B

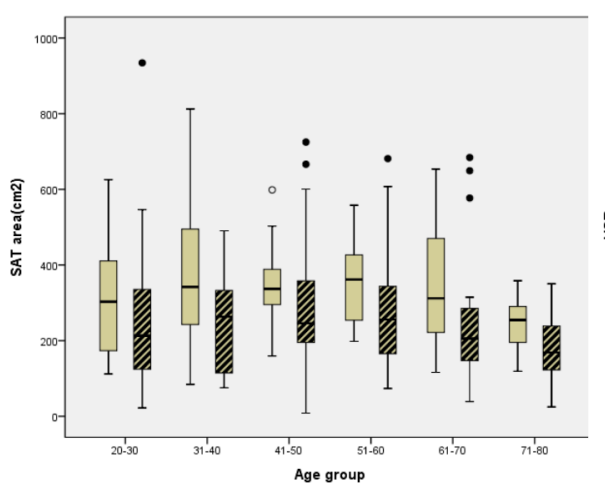

c

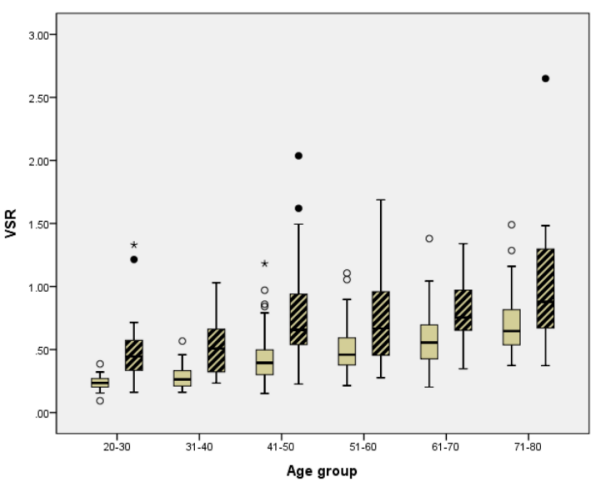

Figure 2 Quartiles of visceral adipose tissue (VAT), subcutaneous adipose tissue (SAT) and visceral-to-subcutaneous fat ratios (VSRs) according to age group and sex (empty columns, women; hatched columns, men). (A) VAT. (B) SAT. (C) VSR.

\section{ROC analysis and threshold values of VAT and VSR using} markers of metabolic complications

To evaluate the usefulness of BMI, VAT, SAT and VSR as predictive markers of metabolic complications, ROC curves were used to calculate the AUC for these variables (table 3). The AUCs that predicted MES were statistically significant for VAT and VSR for both men and women. The AUCs of BMI and SAT were not statistically significant. These data suggest that the VAT or VSR were better than BMI or SAT in discriminating subjects at risk of MES. Overall, AUC values were greater in men than in women for VAT, SAT and VSR. The AUCs to predict high BP and high FPG were statistically significant for VAT and VSR but not for SAT among men and women. AUCs used to identify high TG or low HDL-C were not significant for any adipose tissue parameters in men. In women, AUCs used to identify high TG or low HDL-C were significant only for VSR (high TG) and VAT (low HDL-C). When subjects with abdominal adipose areas greater than the field of view were excluded prior to ROC analysis, there were small changes in overall AUC values without any change in statistical significance (online supplementary table A).

Online supplementary table A shows areas under the ROC curve for VAT, SAT and VSR used to identify metabolic complications among subjects with adequate abdominal adipose area regions of interest.

In table 4, threshold values of adipose tissue areas were obtained to predict MES after dividing subjects into two groups based on their age, since VAT values increased with age for those under 50 years of age and remained constant thereafter. The cut-off value of VAT was

Table 2 Comparison of the metabolic complications and adipose tissue areas between subjects with and without MES except waist circumference

\begin{tabular}{|c|c|c|c|c|c|c|}
\hline & \multicolumn{3}{|l|}{ Female $(\mathrm{N}=192)$} & \multicolumn{3}{|l|}{ Male $(\mathrm{N}=177)$} \\
\hline & $\begin{array}{l}\text { None or one } \\
\text { metabolic risk } \\
\text { factor }(\mathrm{N}=51)\end{array}$ & $\begin{array}{l}\text { Two or more } \\
\text { metabolic risk } \\
\text { factors }(\mathrm{N}=141)\end{array}$ & $P$ value & $\begin{array}{l}\text { None or one } \\
\text { metabolic risk } \\
\text { factor }(\mathrm{N}=38)\end{array}$ & $\begin{array}{l}\text { Two or more } \\
\text { metabolic risk } \\
\text { factors }(\mathrm{N}=139)\end{array}$ & $P$ value \\
\hline Age (years) & $42.9 \pm 12.9$ & $54.2 \pm 14.4$ & $<0.001$ & $44.3 \pm 17.5$ & $55.2 \pm 14.2$ & $<0.001$ \\
\hline BMI $\left(\mathrm{kg} / \mathrm{m}^{2}\right)$ & $30.9 \pm 8.9$ & $32.8 \pm 8.3$ & 0.178 & $27.6 \pm 8.2$ & $28.9 \pm 6.5$ & 0.328 \\
\hline $\begin{array}{l}\mathrm{BP} \geq 130 / 85 \mathrm{~mm} \mathrm{Hg} \text { or } \\
\text { medication }\end{array}$ & $9(17.6)$ & 98 (69.5) & $<0.001$ & $5(13.2)$ & $106(76.3)$ & $<0.001$ \\
\hline High FPG, N (\%) & $11(21.6)$ & $129(91.5)$ & $<0.001$ & $11(28.9)$ & $127(91.4)$ & $<0.001$ \\
\hline High TG, N (\%) & $1(2.0)$ & $57(40.4)$ & $<0.001$ & $3(7.9)$ & $45(32.4)$ & 0.003 \\
\hline Low HDL-C, N (\%) & $12(23.5)$ & $108(76.6)$ & $<0.001$ & $5(13.2)$ & $90(64.7)$ & $<0.001$ \\
\hline $\begin{array}{l}\text { Greater SAT area than the } \\
\text { field of view, N (\%) }\end{array}$ & $27(52.9)$ & $72(51.1)$ & 0.818 & $8(21.1)$ & $17(12.2)$ & 0.166 \\
\hline
\end{tabular}

${ }^{*}$ Means \pm SE are adjusted for age in same-gender group.

BMI, body mass index; BP, blood pressure; FPG, fasting plasma glucose; HDL-C, high-density lipoprotein cholesterol; SAT, subcutaneous adipose tissue; TG, triglyceride; VAT, visceral adipose tissue; VSR, visceral-to-subcutaneous fat ratio. 
Table 3 Areas under the ROC curve of the VAT, SAT and VSR to identify the metabolic complications

Female ( $\mathrm{N}=192)$

AUC

MES except waist circumference

$\begin{array}{lrrrrrr}\text { BMI } & 0.566 & 0.165 & 0.472 \text { to } 0.660 & 0.608 & 0.045 & 0.498 \text { to } 0.718 \\ \text { VAT } & 0.706 & <0.001 & 0.624 \text { to } 0.788 & 0.742 & <0.001 & 0.651 \text { to } 0.834 \\ \text { SAT } & 0.531 & 0.508 & 0.438 \text { to } 0.625 & 0.593 & 0.083 & 0.481 \text { to } 0.705 \\ \text { VSR } & 0.685 & <0.001 & 0.602 \text { to } 0.769 & 0.695 & <0.001 & 0.598 \text { to } 0.792\end{array}$

High BP

\begin{tabular}{|c|c|c|c|c|c|c|}
\hline BMI & 0.511 & 0.790 & 0.429 to 0.594 & 0.599 & 0.030 & 0.513 to 0.685 \\
\hline VAT & 0.702 & $<0.001$ & 0.628 to 0.776 & 0.710 & $<0.001$ & 0.630 to 0.791 \\
\hline SAT & 0.472 & 0.501 & 0.389 to 0.554 & 0.585 & 0.061 & 0.496 to 0.674 \\
\hline \multicolumn{7}{|c|}{ High FPG } \\
\hline BMI & 0.558 & 0.217 & 0.461 to 0.655 & 0.574 & 0.160 & 0.466 to 0.682 \\
\hline SAT & 0.524 & 0.605 & 0.430 to 0.618 & 0.561 & 0.247 & 0.448 to 0.674 \\
\hline VSR & 0.675 & $<0.001$ & 0.593 to 0.758 & 0.710 & $<0.001$ & 0.609 to 0.810 \\
\hline \multicolumn{7}{|c|}{ High TG } \\
\hline BMI & 0.498 & 0.963 & 0.411 to 0.585 & 0.566 & 0.185 & 0.471 to 0.661 \\
\hline \multicolumn{7}{|c|}{ Low HDL-C } \\
\hline BMI & 0.567 & 0.123 & 0.481 to 0.653 & 0.541 & 0.350 & 0.453 to 0.629 \\
\hline VAT & 0.609 & 0.011 & 0.527 to 0.692 & 0.552 & 0.242 & 0.465 to 0.639 \\
\hline SAT & 0.549 & 0.264 & 0.462 to 0.635 & 0.508 & 0.862 & 0.420 to 0.596 \\
\hline VSR & 0.570 & 0.105 & 0.485 to 0.655 & 0.552 & 0.236 & 0.465 to 0.640 \\
\hline
\end{tabular}

AUC, area under the curve; BMI, body mass index; BP, blood pressure; FPG, fasting plasma glucose; HDL-C, high-density lipoprotein cholesterol; ROC, receiver-operating characteristics; SAT, subcutaneous adipose tissue; TG, triglyceride; VAT, visceral adipose tissue; VSR, visceral-to-subcutaneous fat ratio.

$132.0 \mathrm{~cm}^{2}$ in men or women under 50 years of age, and thus we assumed that if VAT was greater than $132.0 \mathrm{~cm}^{2}$, study subjects were more likely to have MES. For subjects in the over 50 years of age group, the VAT threshold was

Male ( $\mathbf{N = 1 7 7 )}$

AUC $\quad$ P value $\quad 95 \% \mathrm{Cl}$

Table 4 The cut-off values for VAT and VSR to identify MES by gender and age subgroup

\begin{tabular}{|c|c|c|c|c|c|c|c|c|}
\hline & \multicolumn{4}{|c|}{ Female $(\mathrm{N}=192)$} & \multicolumn{4}{|l|}{ Male $(\mathrm{N}=177)$} \\
\hline & $\begin{array}{l}\text { Cut-off } \\
\text { value }\left(\mathrm{cm}^{2}\right)\end{array}$ & $\begin{array}{l}\text { Sensitivity } \\
(\%)\end{array}$ & $\begin{array}{l}\text { Specificity } \\
(\%)\end{array}$ & $P$ value & $\begin{array}{l}\text { Cut-off value } \\
\left(\mathrm{cm}^{2}\right)\end{array}$ & $\begin{array}{l}\text { Sensitivity } \\
(\%)\end{array}$ & $\begin{array}{l}\text { Specificity } \\
(\%)\end{array}$ & $P$ value \\
\hline Age $\leq 50$ years & 132.0 & 54.0 & 86.5 & $<0.001$ & 132.0 & 74.0 & 76.0 & $<0.001$ \\
\hline Age $>50$ years & 173.0 & 51.3 & 78.6 & 0.313 & 124.3 & 78.7 & 61.5 & 0.017 \\
\hline Age $>50$ years & 0.647 & 37.2 & 85.7 & 0.422 & 0.693 & 59.6 & 69.2 & 0.165 \\
\hline
\end{tabular}

MES, metabolic syndrome; VAT, visceral adipose tissue; VSR, visceral to subcutaneous fat ratio. 
of age were $0.293(p<0.01)$ in women and $0.424(p<0.01)$ in men. However, after 50 years of age the threshold values were increased to $0.647(\mathrm{p}=0.422)$ and $0.693(\mathrm{p}=0.165)$ in women and men, respectively. The sensitivity of VSR was $37.2 \%$ and thus may have limited utility in identifying metabolic complications in women over 50 years of age. When we excluded subjects with abdominal adipose areas greater than the field of view and performed ROC analyses, the cut-off values of VAT used to predict MES decreased for subjects under 50 years of age (online supplementary table B).

Online supplementary table B shows cut-off values for VAT and VSR used to identify MES stratified by sex and age among subjects with adequate abdominal adipose area regions of interest.

\section{DISCUSSION}

The results of this study showed that the cut-off value of VAT to predict MES was $132 \mathrm{~cm}^{2}$ for individuals under 50 years of age living in the UAE. Furthermore, we found that older age had different effects on the threshold values of VAT and VSR for women compared with men. Definitive cut-off values for VSR are difficult to establish in obese patients with variability in SAT measures as was seen in this study population.

Our thresholds for VAT in subjects under 50 years of age were within the range of those identified in previous studies of various ethnic populations. Katzmarzyk et $a \tilde{l}$ identified a threshold of $140 \mathrm{~cm}^{2}$ as a marker for cardiometabolic risk in a sample of white men and women. Lee $e t a{ }^{\ominus}$ proposed cut-off values for identifying MES risk as $134 \mathrm{~cm}^{2}$ and $91 \mathrm{~cm}^{2}$ for Korean adult men and women, respectively. In a study of Japanese adult men and women, the optimal cut-off points for VAT identifying MES was $132 \mathrm{~cm}^{2}$ and $91 \mathrm{~cm}^{2},{ }^{16}$, respectively. Similarly, in a 4-year follow-up study among middle-aged Turkish patients, a VAT of $130 \mathrm{~cm}^{2}$ was determined to be the optimal cutoff value to predict occurrence of diabetes or coronary heart disease. ${ }^{7}$ The small differences in threshold values in these studies were likely due to differences in measurement protocols for VAT, variables used to assess metabolic risks or analytical approaches used to determine the thresholds. These studies further corroborate the idea that critical thresholds for VAT may be present despite individual and ethnic variation. ${ }^{4}$

MES is prevalent among Emirati adults with a previous study finding that more than $40 \%$ of overweight or obese adults between 18 and 50 years old had MES. ${ }^{17}$ Similarly, the prevalence of MES was also found to be high among obese people $(34.5 \%)$ of younger age. ${ }^{18}$ In this study, more than $70 \%$ of subjects had metabolic complications, and many of these patients were likely to have insulin resistance since they had high BMI and high prevalence of hypertension or diabetes. It is notable that the VAT threshold from our study was comparable to that obtained from studies examining study populations of different ethnicities. It is well known that the metabolic profiles of patients with visceral obesity may substantially improve after only modest amounts weight loss. ${ }^{419}$ VAT thresholds identified in populations already experiencing metabolic complications may provide goals that could be used to reduce those complications. Using these VAT thresholds, we expect that individuals living in the UAE working to reduce their respective VAT values below the thresholds could reduce their metabolic complications.

In contrast to previous studies, the mean SAT areas of our study subjects with or without MES were higher ${ }^{5916}$ and, therefore, VSR values were smaller than those obtained in previous studies. ${ }^{2021}$ Interestingly, VSR of our subjects, like VAT, was able to predict high BP and high FPG. A recent study showed that VSR had a better performance of predicting incident or recurrent cardiovascular disease than BMI or VAT among patients with type 2 diabetes. ${ }^{22}$ Although we could not establish common thresholds for VSR in our subjects, VSR may be a useful indicator associated with metabolic abnormalities in population with abundant abdominal fat as well as in lean populations. Further studies examining more diverse populations with metabolic risk factors and adipose tissue distributions should be conducted to establish the pathophysiological role of adipose tissue characteristics. ${ }^{23}$

Several studies have reported that VAT thresholds for metabolic complications vary with age. ${ }^{89}$ In the current study, women over 50 years of age had a greater VAT threshold $\left(173 \mathrm{~cm}^{2}\right)$ compared with men of the same age $\left(124.3 \mathrm{~cm}^{2}\right)$ or younger individuals. It is unclear whether this difference is age dependent or if the relationship of VAT to metabolic complications is more prominent in older women. In the UK Biobank study, over 500000 participants aged 40-69 years were recruited to assess the relationship between central adiposity measures and risk of myocardial infarction and it was found that risk varied in a sex-dependent manner. ${ }^{24}$ It is well known that adipose tissue distribution markedly differs between men and women. Recent evidence showed that sex-specific differences are a result of differential gene expression patterns in VAT and SAT, and these changes go beyond the differences in size of anatomic depot. ${ }^{25}$ The interactions of adipose tissue, sex and ageing have not been investigated in detail and this area warrants further study.

To the best of our knowledge, this is the first study to investigate VAT thresholds for metabolic complications related to obesity in a UAE-derived study population. We reviewed medical records of all patients who underwent abdominal CT scans across a 2-year study period and excluded cases with underlying factors that could affect visceral fat. Participants were limited to people with UAE nationality or those who were ethnically from the Middle East. However, our study also has limitations. First, the participants were recruited from a single medical centre in the UAE, thereby limiting the broad generalisability of our findings to other study populations. Nevertheless, the VAT threshold values presented in this study were not different from that of previously reported studies. Second, more than half of the women in our study had greater 
SAT areas than the CT imaging field of view. However, if we include only women with an appropriate region of interest in the analysis, the results cannot be used to represent women with increased SAT in this study population. Third, because information on the medical history was identified by retrospective chart reviews, potential misclassification biases may exist. Lastly, waist circumference, an important marker for abdominal obesity, was not measured in this study since it was not available in the medical record. It is possible that the prevalence of metabolic complications were overestimated since we applied IDF criteria of MES and excluded waist circumference measures.

In summary, this study provided a CT-defined VAT threshold for populations that experienced metabolic complications, including diabetes and MES. Our findings could be used to suggest a target value for visceral fat in order to reduce obesity-related complications. Future studies are needed to determine the target value for waist circumference and other methods of measuring VAT, since application of CT for measuring VAT is limited in the clinical setting.

\section{Author affiliations \\ ${ }^{1}$ Department of Family Medicine, Inje University Haeundae Paik Hospital, Busan, The Republic of Korea \\ ${ }^{2}$ Department of Otorhinolaryngology Head and Neck Surgery, Seoul National University College of Medicine, Seoul, The Republic of Korea \\ ${ }^{3}$ Department of ENT, Sheikh Khalifa Specialty Hospital, Ras Al Khaimah, United Arab Emirates \\ ${ }^{4}$ Department of Imaging and Laboratory, Sheikh Khalifa Specialty Hospital, Ras Al Khaimah, United Arab Emirates \\ ${ }^{5}$ Department of Radiology, Ulsan University Hospital, Ulsan, The Republic of Korea}

Contributors SY conceived of the study, participated in the data collection, undertook statistical analyses and drafted the manuscript. HK participated in the data collection, drafted the manuscript and supervised the study. M-WS participated in the design of the study. All authors were involved in writing the paper and had final approval of the submitted and published versions.

Funding This work was supported by the 2017 Research Year grant of Inje University (Grant No. 20170047) and was conducted at the Sheikh Khalifa Specialty Hospital in the United Arab Emirates.

\section{Competing interests None declared.}

Patient and public involvement Patients and/or the public were not involved in the design, or conduct, or reporting, or dissemination plans of this research.

Patient consent for publication Not required.

Ethics approval This study was approved by the Sheikh Khalifa Specialty Hospital's Institutional Review Board (SKSH-1806-007-003).

Provenance and peer review Not commissioned; externally peer reviewed.

Data availability statement Data are availale upon resonable request.

Open access This is an open access article distributed in accordance with the Creative Commons Attribution Non Commercial (CC BY-NC 4.0) license, which permits others to distribute, remix, adapt, build upon this work non-commercially, and license their derivative works on different terms, provided the original work is properly cited, appropriate credit is given, any changes made indicated, and the use is non-commercial. See: http://creativecommons.org/licenses/by-nc/4.0/.

\section{ORCID iD}

Sunmi Yoo http://orcid.org/0000-0001-7407-8423

\section{REFERENCES}

1 Ibrahim MM. Subcutaneous and visceral adipose tissue: structural and functional differences. Obes Rev 2010;11:11-18.

2 Britton KA, Fox CS. Ectopic fat depots and cardiovascular disease. Circulation 2011;124:e837-41.

3 Smith U. Abdominal obesity: a marker of ectopic fat accumulation. J Clin Invest 2015;125:1790-2.

4 Freedland ES. Role of a critical visceral adipose tissue threshold (CVATT) in metabolic syndrome: implications for controlling dietary carbohydrates: a review. Nutr Metab 2004;1:12.

5 Katzmarzyk PT, Heymsfield SB, Bouchard C. Clinical utility of visceral adipose tissue for the identification of cardiometabolic risk in white and African American adults. Am J Clin Nutr 2013;97:480-6.

6 Lear SA, Humphries KH, Kohli S, et al. Visceral adipose tissue accumulation differs according to ethnic background: results of the multicultural community health assessment trial (M-CHAT). Am J Clin Nutr 2007;86:353-9.

7 Onat A, Uğur M, Can G, et al. Visceral adipose tissue and body fat mass: predictive values for and role of gender in cardiometabolic risk among turks. Nutrition 2010;26:382-9.

8 Matsushita Y, Nakagawa T, Yamamoto S, et al. Visceral fat area cutoff for the detection of multiple risk factors of metabolic syndrome in Japanese: the Hitachi health study. Obesity 2012;20:1744-9.

9 Lee A, Kim YJ, Oh S-W, et al. Cut-Off values for visceral fat area identifying Korean adults at risk for metabolic syndrome. Korean $J$ Fam Med 2018;39:239-46.

10 Newton RL, Bouchard C, Bray G, et al. Abdominal adiposity depots are correlates of adverse cardiometabolic risk factors in Caucasian and African-American adults. Nutr Diabetes 2011;1:e2.

11 NCD Risk Factor Collaboration (NCD-RisC). Worldwide trends in body-mass index, underweight, overweight, and obesity from 1975 to 2016: a pooled analysis of 2416 population-based measurement studies in 128.9 million children, adolescents, and adults. Lancet 2017;390:2627-42.

12 International Diabetes Federation. IDF diabetes atlas. 8th edn. Brussels, Belgium, 2017.

13 Blair I, Sharif AA. Population structure and the burden of disease in the United Arab Emirates. J Epidemiol Glob Health 2012;2:61-71.

14 Smith SR, Lovejoy JC, Greenway F, et al. Contributions of total body fat, abdominal subcutaneous adipose tissue compartments, and visceral adipose tissue to the metabolic complications of obesity. Metabolism 2001;50:425-35.

15 International Diabetes Federation. The IDF consensus worldwide definition of the metabolic syndrome. Brussels, Belgium, 2017.

16 Oka R, Kobayashi J, Yagi K, et al. Reassessment of the cutoff values of waist circumference and visceral fat area for identifying Japanese subjects at risk for the metabolic syndrome. Diabetes Res Clin Pract 2008;79:474-81.

17 Al-Sarraj T, Saadi H, Volek JS, et al. Metabolic syndrome prevalence, dietary intake, and cardiovascular risk profile among overweight and obese adults 18-50 years old from the United Arab Emirates. Metab Syndr Relat Disord 2010;8:39-46.

18 Al Dhaheri AS, Mohamad MN, Jarrar AH, et al. A cross-sectional study of the prevalence of metabolic syndrome among young female Emirati adults. PLoS One 2016;11:e0159378.

19 Shulman Gl. Ectopic fat in insulin resistance, dyslipidemia, and cardiometabolic disease. N Engl J Med 2014;371:1131-41.

$20 \mathrm{Oh} \mathrm{YH}$, Moon JH, Kim HJ, et al. Visceral-to-subcutaneous fat ratio as a predictor of the multiple metabolic risk factors for subjects with normal waist circumference in Korea. Diabetes Metab Syndr Obes 2017;10:505-11.

$21 \mathrm{Kim}$ S, Cho B, Lee H, et al. Distribution of abdominal visceral and subcutaneous adipose tissue and metabolic syndrome in a Korean population. Diabetes Care 2011;34:504-6.

22 Fukuda T, Bouchi R, Takeuchi T, et al. Ratio of visceral-tosubcutaneous fat area predicts cardiovascular events in patients with type 2 diabetes. J Diabetes Investig 2018;9:396-402.

23 Grundy SM. Adipose tissue and metabolic syndrome: too much, too little or neither. Eur J Clin Invest 2015;45:1209-17.

24 Peters SAE, Bots SH, Woodward M. Sex differences in the association between measures of general and central adiposity and the risk of myocardial infarction: results from the UK Biobank. J Am Heart Assoc 2018;7:e008507.

25 Valencak TG, Osterrieder A, Schulz TJ. Sex matters: the effects of biological sex on adipose tissue biology and energy metabolism. Redox Biol 2017;12:806-13. 